\title{
Evaluation of nutritive value and in vitro rumen fermentation gas accumulation of de-oiled algal residues
}

Kun Jun $\operatorname{Han}^{1 *}$ and Michael E McCormick ${ }^{2}$

\begin{abstract}
Background: Algae are widely recognized for their high oil content and for exponentially accumulating biomass with particular potential to provide single cell protein for human consumption or animal feed. It is believed that along with biodiesel from algae, the high protein de-oiled algal residue may become an alternative feed supplement option in the future. This study was conducted to investigate de-oiled algal residue obtained from the common Chlorella species, Thalassiosira weissflogii, Selenarstrum capricornutum, Scenedesmus sp., and Scenedesmus dimorphus for assessment as potential feed supplements for ruminants by comparing with soybean (Glycine max) meal and alfalfa (Medicago sativa) hay.

Results: With the exception of T. weissflogii, algal residue had higher concentrations of $\mathrm{Cu}, \mathrm{Zn}$, and $\mathrm{Mn}$ and lower concentration of $\mathrm{Ca}, \mathrm{Mg}$, and $\mathrm{K}$ than soybean meal and alfalfa hay. The algal residue CP (crude protein) concentrations ranged from 140 to $445 \mathrm{~g} / \mathrm{kg} \mathrm{DM}$ and varied among the de-oiled residues. In vitro rumen fermentation gas accumulation curves indicated that algal biomass degradation potential was less than that of soybean meal or alfalfa hay by up to $41.7 \%$.

The gas production curve, interpreted with a dual pool logistic model, confirmed that the fraction sizes for fast fermenting and slow fermenting of de-oiled algal residues were smaller than those in soybean meal and alfalfa hay, and the fermenting rate of the fractions was also low.
\end{abstract}

Conclusions: Inferior in vitro rumen gas accumulation from the five de-oiled algal residues suggests that these algal byproducts are less degradable in the rumen.

Keywords: Crude protein, De-oiled algal residue, Feed supplement, in vitro rumen fermentation gas, Macro mineral, Micro mineral

\section{Background}

An extended grazing period with mature grasses or summer grazing with warm-season grasses usually does not sate the requirement on protein and energy for actively growing heifers and milking cows because of low nutrient concentration and low DM intake [1]. Supplement programs boosting protein, energy, or minerals are commonly practiced in livestock operations when feeding cattle with low quality forage. Well managed supplement programs increase DM intake of forage and ultimately

\footnotetext{
* Correspondence: Khan@agcenter.lsu.edu

'Louisiana State University Agricultural Center, School of Plant, Environmental, and Soil Sciences, 104 M.B. Sturgis Hall, Baton Rouge, LA 70803, USA

Full list of author information is available at the end of the article
}

improve livestock performance. Byproducts from algae biomass can be utilized as a protein supplement because of high CP concentration [2]. However, an algae based feed supplement program is not yet fully available for cattle operations due to high production costs [3]. Along with biofuel production from large biomass producing field crops, liquid fuel production from algae has demonstrated great potential due to its high water use efficiency and rapid biomass accumulation ability. Although there are still technical obstacles to overcome to achieve mass production and processing of algae in a sustainable way, theoretically, it has been estimated that in Europe alone, 0.4 billion liters of diesel can be supplied through algae-originated biodiesel in the next ten to fifteen years [4]. Through the production of algae protein, which may 
become one of the most economical protein supplement options for livestock operations. In spite of algae's high protein concentration, low digestibility or lack of sulfurcontaining amino acids was reasoned to cause the lower growth rate of monogastric animals fed on algae containing diet when compared with that of those fed on a casein based control diet [5]. Stability of single cell protein protected by a cellulose enriched cell membrane has been implicated as a limiting factor in low nutritional value in monogastric animals $[6,2,7,4]$. In contrast with testing results with monogastric animals, feeding Spirulina platensis as a supplement along with low CP containing guinea grass [Panicum maximum (synn. Urocloa maxima)] hay improved efficiency of microbial protein production in cattle [8]. The lack of animal performance response to high nutritive value algae byproduct necessitates more research efforts focusing on the factors limiting utilization efficiency of algae byproducts [9]. Unlike the somewhat disappointing utilization results in monogastric animal feeding trials, cell wall protected algae protein may be beneficial to ruminants due to the fiber degradation ability of rumen microbes. The objective of this research was to assess potential nutritional value of de-oiled algal residues as a ruminant feed supplement by comparing $\mathrm{CP}$, minerals, and in vitro rumen fermentation gas accumulation characteristics with those of commonly utilized feed supplements such as soybean meal and alfalfa hay.

\section{Methods}

\section{Preparation of de-oiled algal residue}

The following algae samples were obtained in pure form from the University of Texas Culture Collection of Algae (UTEX) Austin, TX, USA: S. capricornutum, Scenedesmus sp. and S. dimorphus. Thalassiosira weissflogii, a diatom, was obtained from the Provasoli-Guillard National Center for Marine Algae and Microbiota, East Boothbay, ME, USA. Common Chlorella species collected in Baton Rouge, Louisiana, USA was also cultivated. All species were initially grown indoors in triplicate $1 \mathrm{~L}$ flasks in an incubation chamber at $25^{\circ} \mathrm{C} \pm 2^{\circ} \mathrm{C}$ with a $12 \mathrm{~h}$ photoperiod illuminated to $500 \mu \mathrm{mol}$ photons $/ \mathrm{m}^{2} / \mathrm{s}$ with fluorescent lights. Guillard's (F/2) marine water enrichment solution (Sigma-Aldrich, Cat\# G0154) was used as a cultural media. For T. weissflogii, a marine species, Instant Ocean ${ }^{\mathrm{Tt}}$ was used bring the salinity to $35 \mathrm{ppt}$. After one week, cultures were moved outdoors into $55 \mathrm{~L}$ vessels and grown for two additional weeks. Culture density was monitored at $8 \mathrm{~h}$ intervals and optimum harvest time was determined after two successive "no growth" biomass measurement recordings. The cultures were centrifuged at 3,000 rpm to concentrate the solids content to approximately $2 \% \mathrm{ds}$, and then further concentrated to $10 \%$ ds by centrifuging at 7,000 rpm for $10 \mathrm{~min}$. Harvested algal biomass paste was dried on aluminum weigh pans in a forced-air oven at $55^{\circ} \mathrm{C}$ for $48 \mathrm{~h}$ until no further weight loss was measured. Since the study goal is to estimate feed supplement value of algae byproduct, the de-oiling process was applied to dried algae simulating the algal residue utilization after biodiesel extraction. Oil was extracted from the dried algal biomass using a SoxTec 2050 (FOSS, Eden Prairie, MN, USA) with hexane (99.9\% HPLC grade) as the solvent for a $12 \mathrm{~h}$ reflux time. Residual solvent in biomass was evaporated under a laminar flow hood for $48 \mathrm{~h}$ to leave de-oiled algal residue.

\section{Analysis of crude protein (CP), neutral detergent fiber (NDF), and mineral in samples}

De-oiled algae samples, commercially available soybean meal, and alfalfa hay were ground through a $1-\mathrm{mm}$ screen and analyzed for Kjeldahl $\mathrm{N}$ and $\mathrm{P}$ in an automated colorimetric assay adapted for flow-injection analyzer (QuickChem 8000 FIA, Lachat Instruments, Milwaukee, WI, USA) according to [10] procedures. The $C P$ in samples was calculated as total $\mathrm{N} \times 6.25$ and NDF was determined with an Ankom Model 200 fiber analyzer (Ankom Technology, Macedon, NY, USA) using a sodium sulphite procedure [11]. Mineral concentration was determined by flame atomic absorption spectrophotometry (Perkin-Elmer Analyst 300, Norwalk, CT, USA) after dry ashing at $500^{\circ} \mathrm{C}$ overnight in porcelain crucibles.

\section{Determination of coefficient for in vitro fermentation gas production}

The protocol used in this research was approved by the Louisiana State University Agricultural Center Protocol for Animal Care and Use Committee (IACUC Approval \# A2012-14). The rumen fluid was collected from a cannulated Holstein heifer fed mixed alfalfa hay and grass hay. Quadruplicate $0.50 \mathrm{~g}$ samples were analyzed for in vitro fermentation gas analysis according to [12]. The whole incubation was processed at $39^{\circ} \mathrm{C}$, and gas readings for each incubation bottle were recorded at $30 \mathrm{~min}$ intervals using Ankom Gas Module (Ankom Technology, Macedon, NY, USA). Rate and extent of fermentation gas production were determined for each sample by fitting the gas production data to the dual pool logistic equation [13]:

$$
\begin{aligned}
V= & V_{\mathrm{F} 1}\left(1+\exp \left(2+4 \mu_{\mathrm{m} 1} / V_{\mathrm{F} 1} \times\left(\lambda_{1}-t\right)\right)\right)^{-1} \\
& +V_{\mathrm{F} 2}\left(1+\exp \left(2+4 \mu_{\mathrm{m} 2} / V_{\mathrm{F} 2} \times\left(\lambda_{2}-t\right)\right)\right)^{-1}
\end{aligned}
$$

where $V$ is the amount of gas production at time $t$, and $V_{\mathrm{F} 1}$ and $V_{\mathrm{F} 2}$ are the final gas production volumes corresponding to complete substrate digestion for a rapidly fermenting pool and a slowly fermenting pool, respectively. $\mu_{\mathrm{m} 1}$ and $\mu_{\mathrm{m} 2}$ are the points of inflection of the gas curve for the two pools, respectively. $\lambda_{1}$ and $\lambda_{2}$ are the lag times of the two pools. 


\section{Statistical analysis}

Data for various algal residues were analyzed using the Proc Glimmix of SAS version 9.2 [14]. Differences between least square means were tested using Satterthwaite approximation for the denominator degrees of freedom as an option. Quadruplicate laboratory analyses were conducted for in vitro gas production analysis. Four runs of gas measurements within variation less than $\pm 5 \%$ at $72 \mathrm{~h}$ incubation were used for the analysis. Data fitting a non-linear model were analyzed using Proc NLIN of SAS [14], which was developed by Dr. P. J. Weimer (personal communication).

\section{Results and discussion}

\section{Crude protein in de-oiled algal residue}

Since dried algae are bound to contain variable amounts of protein embedded by cellulosic membrane and considerable oil (up to $350 \mathrm{~g} / \mathrm{kg} \mathrm{DM}$ ), it follows that the major substrate of de-oiled algal residue would consist of protein (as $\mathrm{CP}$ ), cell content (mostly non-fibrous carbohydrate), and fibrous carbohydrate (as NDF). The NDF concentration in de-oiled algal residues ranged from 82 to $180 \mathrm{~g} / \mathrm{kg} \mathrm{DM}$ (Figure 1). The NDF in soybean meal used as one of the control feed supplements averaged $106 \mathrm{~g} / \mathrm{kg}$ DM which did not differ from the NDF concentrations in de-oiled algal residues while the NDF in alfalfa hay was $450 \mathrm{~g} / \mathrm{kg}$ DM.

There was a substantial variation in $\mathrm{CP}$ concentrations among the de-oiled algal residues (Figure 1). The CP concentrations in S. capricornutum, Scenedesmus sp. and $S$. dimorphus were equivalent to that in soybean meal. The CP concentration in Chlorella residue was between that of soybean and alfalfa hay $(P<0.01)$. The $C P$ in $T$. weissflogii was similar to that in alfalfa hay. As the present study and Piorreck et al. [2] pointed out, protein concentrations of most algal residues are above $300 \mathrm{~g} / \mathrm{kg} \mathrm{DM}$, indicating that tested algal residues may be considered as high protein supplements.

Besides cellulosic membrane embedded protein issue, [7] pointed out that around 10\% of Scenedesmus and Spirulina DM was non-protein nitrogen which is not an available protein form for monogastric animals. Therefore, the determination of $\mathrm{CP}$ based on total nitrogen in algae DM resulted in overestimation of available protein for maintenance and growth in monogastric animals, but this form of $\mathrm{N}$ is still effective in ruminants as a $\mathrm{N}$ source for generation of rumen microbial protein. The benefit of successful byproduct supplement programs can be realized through providing greater RUP (rumen un-degradable protein) in a cost effective manner [15]. Increasing RUP in a diet of early lactation stage cows could produce more milk without additional grain intake [16]. As Becker [7] pointed out, with the cellulosic cell wall component as the most limiting factor for algae protein digestion and utilization, algae protein embedded in the cellulosic membrane may provide more feeding value to ruminant animals than monogastric animals.

\section{Mineral concentration in de-oiled algal residue}

Mineral concentration aspects in $T$. weissflogii were unique from other algal residues. De-oiled residue from T. weissflogii contained greater concentrations of $\mathrm{Ca}$, $\mathrm{Mg}, \mathrm{Cu}, \mathrm{Zn}$, and $\mathrm{Mn}$ than those in two conventional feed supplements. Comparing with the minerals in tested algal residue, $T$. weissflogii contains much greater concentrations of $\mathrm{Ca}, \mathrm{Mg}, \mathrm{K}$, and $\mathrm{Zn}$. Generally, the $\mathrm{Ca}$ in other de-oiled algal residue was approximately half of that in soybean meal or one fourth of that in alfalfa hay

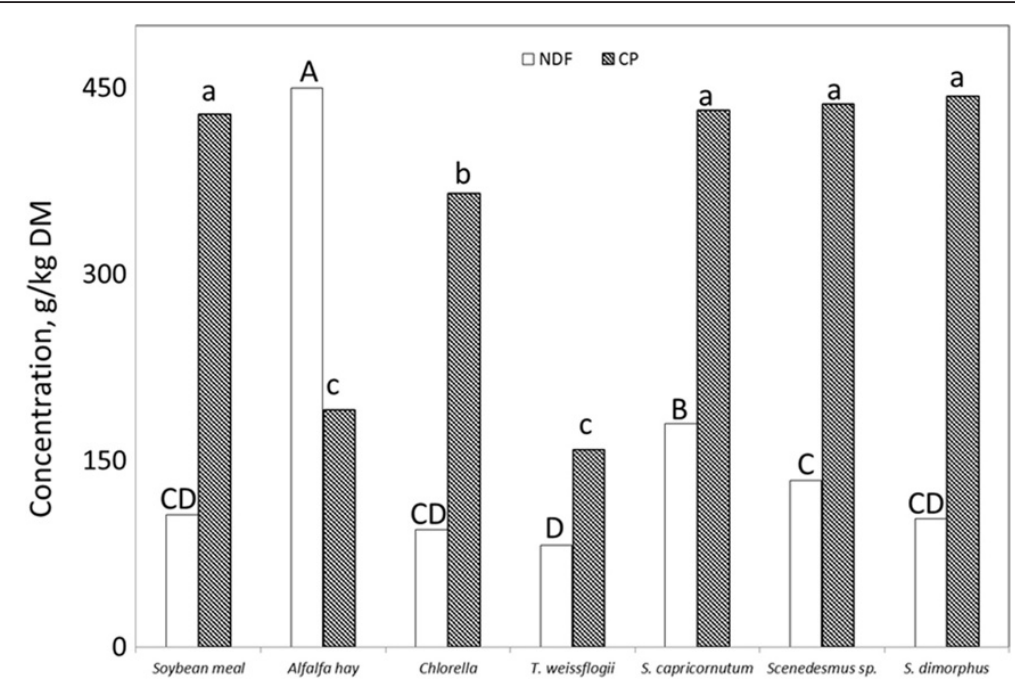

Figure 1 NDF and CP in soybean meal, alfalfa hay, and de-oiled algae residues. Within neutral detergent fiber (NDF) or within crude protein $(C P)$, bars without a common letter differ $(P<0.05)$. 
(Table 1). Phosphorus concentrations did not show as much variation as $\mathrm{Ca}$ in the five de-oiled algal residues and the two conventional protein supplements. Commonly, in the algal residues and conventional feed supplements, the P concentration converged around $1 \mathrm{~g} / \mathrm{kg}$ DM. The relatively high $\mathrm{P}$ concentration compared with $\mathrm{Ca}$ in algal residues may require feeding extra $\mathrm{Ca}$ to assure a proper Ca-P ratio (2:1) for high performing ruminants [17]. The $\mathrm{Mg}$ concentration in the algal residues was less than that of soybean meal or alfalfa hay except in $T$. weissflogii. Again, except for $T$. weissflogii, the $\mathrm{K}$ concentrations in four algal residues were below detectable limits.

Micro mineral concentrations such as $\mathrm{Cu}, \mathrm{Zn}$, and $\mathrm{Mn}$ in de-oiled algal residues were greater than those of soybean meal or alfalfa hay (Table 1). Except for P, generally low macro mineral concentration but high concentrations of $\mathrm{Cu}, \mathrm{Zn}$, and $\mathrm{Mn}$ may be of concern for use of tested algal residues in animal nutrition. High $\mathrm{Cu}$ in algal residue may be a particular concern with small ruminants and calves because of relatively low tolerant levels appearing in [18]. Also, the high Mn concentration in algal residue may also be a concern for potential Mn toxicity [19].

\section{In vitro rumen fermentation gas accumulation of de-oiled algal residue}

Accumulated in vitro fermentation gas from algal residues were only 40 to $67 \%$ of that from soybean meal at $24 \mathrm{~h}$ and the fermentation gas accumulation curves displayed a nonlinear trend over the incubation period (Figure 2). Gas accumulation of soybean meal and alfalfa hay demonstrated distinctively different patterns from de-oiled algal residues. After the first $3 \mathrm{~h}$ or so of fermentation, gas production values for two control supplements and de-oiled algal residues diverged. The accumulated gas production from soybean meal and alfalfa hay reached asymptote around 18 to $20 \mathrm{~h}$ of incubation.

Based on the assumption of a similar cell wall material and CP concentrations in soybean meal, S. capricornutum,

Table 1 Mineral concentration of de-oiled algal residues, soybean meal, and alfalfa hay

\begin{tabular}{|c|c|c|c|c|c|c|c|}
\hline \multirow[t]{2}{*}{ Supplement } & $\mathrm{Ca}$ & $P$ & $\mathrm{Mg}$ & $\mathrm{K}$ & $\mathrm{Cu}$ & $\mathrm{Zn}$ & $M n$ \\
\hline & \multicolumn{4}{|c|}{ g/kg DM } & \multicolumn{3}{|c|}{$\mathrm{mg} / \mathrm{kg} \mathrm{DM}$} \\
\hline Soybean meal & $0.59^{c \dagger}$ & $0.70^{c}$ & $0.23^{b}$ & $2.43^{b}$ & $14^{c}$ & $49^{c}$ & $27^{d}$ \\
\hline Alfalfa & $1.45^{b}$ & $0.19^{d}$ & $0.29^{b}$ & $3.15^{\mathrm{a}}$ & $10^{d}$ & $17^{d}$ & $53^{d}$ \\
\hline Chlorella & $0.21^{\mathrm{e}}$ & $1.17^{\mathrm{a}}$ & $0.11^{c}$ & $\mathrm{ND}^{\ddagger}$ & $35^{b}$ & $70^{\mathrm{b}}$ & $238^{c}$ \\
\hline T. weissflogii & $7.41^{\mathrm{a}}$ & $0.92^{b}$ & $0.74^{a}$ & $2.38^{\mathrm{b}}$ & $44^{b}$ & $422^{a}$ & $430^{b}$ \\
\hline S. capricornutum & $0.32^{d}$ & $1.00^{\mathrm{ab}}$ & $0.14^{c}$ & ND & $90^{\mathrm{a}}$ & $79^{b}$ & $497^{\mathrm{a}}$ \\
\hline Scenedesmus sp. & $0.27^{\text {de }}$ & $1.06^{\mathrm{ab}}$ & $0.17^{c}$ & ND & $93^{\mathrm{a}}$ & $78^{b}$ & $466^{a b}$ \\
\hline S. dimorphus & $0.27^{\text {de }}$ & $1.11^{\mathrm{a}}$ & $0.15^{c}$ & ND & $77^{\mathrm{a}}$ & $75^{\mathrm{b}}$ & $431^{b}$ \\
\hline
\end{tabular}

${ }^{\dagger}$ Within a column, means without a common superscript differ $(P<0.05)$.

${ }^{\ddagger} \mathrm{ND}$, below detectable limit.

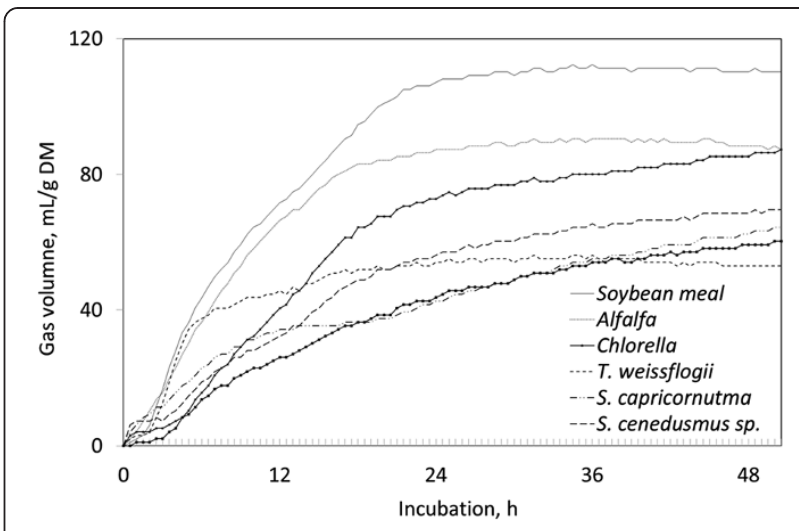

Figure 2 In vitro rumen fermentation gas accumulation curves of tested substrates.

Scendesmus sp., and S. dimorphus, the low gas production from algal residue may indicate less fermentable characteristics of cellulosic structure in the algae cell membrane than in soybean meal. Because gas production maintains a high correlation with volatile fatty acid production from rumen fermentable carbohydrate components in feed samples [20], lower gas production from algal residues than from soybean meal evidenced less fermentable algae cell membrane.

$T$. weissflogii algal residue demonstrated a distinct pattern from other tested algal residues with an early steep rise of fermentation gas accumulation and approached asymptote after a $5 \mathrm{~h}$ incubation. Among the tested algae, $T$. weissflogi grows mainly in a marine environment and in some inland water environments. The different features shown in mineral concentration and gas production in $T$. weissflogii from other tested algae may reflect some unique characteristics of this species related to evolution and growth environment. Scenedesmus $s p$. and S. dimorphus accumulated fermenting gas more steadily. The gas curve pattern of Chlorella was more similar to soybean meal or alfalfa hay even with less accumulation of fermentation gas. Among the de-oiled algal residues, Chlorella produced the most fermentation gas. The de-oiled S. capricornutum, Scenedesmus sp., and S. dimorphus produced almost identical quantities of gas accumulation after a $36 \mathrm{~h}$ incubation.

The logistic model consisting of a fast fermenting fraction and a slow fermenting fraction, as determined by the accumulated fermentation gas, could quantify several coefficients of digestion kinetics in Table 2. The size of the fast fermenting fraction of algal residues of Chlorella was numerically the greatest but not significantly different from that of T. weissflogii, Scenedesmus, and the two control supplements. The fast fermenting fraction of $S$. capricornutum and $S$. dimorphus were smaller than that of Chlorella $(P<0.05)$. As anticipated, the fermentation gas accumulation rate from the fast fermenting fraction was greatest in soybean meal, followed by alfalfa hay and Chlorella $(P<0.01)$. The gas accumulation rate from the 
Table 2 In vitro rumen fermentation gas accumulation kinetics of de-oiled algal residues, soybean meal, and alfalfa hay

\begin{tabular}{|c|c|c|c|c|c|c|c|}
\hline \multirow{3}{*}{ Item } & \multicolumn{2}{|c|}{ Control } & \multicolumn{5}{|c|}{ De-oiled algal residue } \\
\hline & Soybean meal & Alfalfa hay & Common chlorella & T. weissflogii & S. capricornutum & Scenedesmus sp. & S. dimorphus \\
\hline & \multicolumn{7}{|c|}{ Coefficient of in vitro ruminal assay } \\
\hline $\begin{array}{l}\text { Fast fermenting fraction, } \\
\mathrm{mL} / \mathrm{g} \mathrm{DM}\end{array}$ & $57.5^{\mathrm{ab}+}$ & $53.3^{\mathrm{ab}}$ & $70.0^{\mathrm{a}}$ & $53.1^{\mathrm{ab}}$ & $34.5^{\mathrm{b}}$ & $47.6^{\mathrm{ab}}$ & $22.7^{b}$ \\
\hline Fast rate, $\mathrm{mL} / \mathrm{h}$ & $5.00^{\mathrm{a}}$ & $2.81^{b}$ & $2.37^{b}$ & $1.83^{\mathrm{C}}$ & $1.55^{\mathrm{c}}$ & $1.47^{c}$ & $1.29^{c}$ \\
\hline Fast lag, h & $1.78^{\mathrm{a}}$ & $1.42^{\mathrm{a}}$ & $4.47^{\mathrm{a}}$ & $0.20^{\mathrm{a}}$ & $2.01^{\mathrm{a}}$ & $3.34^{\mathrm{a}}$ & $3.01^{\mathrm{a}}$ \\
\hline $\begin{array}{l}\text { Slow fermenting fraction, } \\
\mathrm{mL} / \mathrm{g} \text { DM }\end{array}$ & $63.5^{\mathrm{a}}$ & $38.0^{\mathrm{b}}$ & $22.1^{\mathrm{bc}}$ & $17.3^{c}$ & $31.2^{\mathrm{b}}$ & $37.4^{\mathrm{b}}$ & $37.0^{\mathrm{b}}$ \\
\hline Slow rate, $\mathrm{mL} / \mathrm{h}$ & $2.15^{\mathrm{a}}$ & $1.82^{\mathrm{a}}$ & $0.27^{b}$ & $0.33^{b}$ & $0.38^{\mathrm{b}}$ & $0.34^{b}$ & $0.60^{b}$ \\
\hline Slow lag, h & $6.9^{\mathrm{a}}$ & $3.3^{\mathrm{a}}$ & $8.9^{\mathrm{a}}$ & $3.1^{\mathrm{a}}$ & $16.0^{\mathrm{a}}$ & $14.1^{\mathrm{a}}$ & $7.6^{\mathrm{a}}$ \\
\hline
\end{tabular}

${ }^{\dagger}$ Within a row, means without a common superscript differ $(P<0.05)$.

slow fermenting fraction demonstrated a clearer separation of coefficients between the control supplements and the five algal residues. The fermentation rates of the slow fermenting fractions of soybean meal and alfalfa hay in a rumen were up to eight times greater than those of deoiled algal residues. The lag times for both fractions were not significantly different even with substantial differences among algal residue and with the two control supplements due to variations in individual batches.

\section{Conclusions}

Comparison of fermentation behaviors of de-oiled algal residue with soybean meal and alfalfa hay indicated that carbohydrate in algal residues is less rumen fermentable than those in soybean meal or alfalfa hay. De-oiled algal residue may have potential as a high protein feed supplement which may supply a moderate amount of $\mathrm{N}$ for rumen microbial protein production. However, more research efforts are required for partitioning algal proteins based on rumen degradability. Mineral concentrations, particularly several essential trace minerals, are high, and some caution may be required when used for small ruminants and calves.

\section{Abbreviations}

CP: Crude protein; NDF: Neutral detergent fiber; DM: Dry matter.

\section{Competing interests}

The authors declare that they have no competing interests.

\section{Authors' contributions}

$\mathrm{KJ}$ conducted the study and data interpretation, drafted the initial version of the manuscript. $\mathrm{KJ}$ and $\mathrm{MM}$ revised the manuscript. Both authors read and approved the final manuscript.

\section{Acknowledgements}

This study was supported by Louisiana Board of Regents Research grant. Authors thanks N. Lemoine and C. Lohrey for sharing dried algae biomass, and Drs. P. Weimer and R. Muck for technical support on digestion kinetics model.

\section{Author details}

'Louisiana State University Agricultural Center, School of Plant,

Environmental, and Soil Sciences, 104 M.B. Sturgis Hall, Baton Rouge, LA
70803, USA. ²ouisiana State University Agricultural Center, Southeast Region Office, 21549 Old Covington, Hammond, LA 70403, USA.

Received: 27 January 2014 Accepted: 14 May 2014

Published: 4 June 2014

\section{References}

1. Han KJ, McCormick ME, Walz R: Forage Quality Results from Louisiana and Mississippi producer's Forage Samples, 1999-2006. In Southeast Research Station Field Day Summaries, 2007. Baton Rouge, LA: Louisiana State University Agricultural Center; 2007:35-37.

2. Piorreck M, Baasch K, Pohl P: Biomass production, total protein, chlorophylls, lipids and fatty acids of freshwater green and blue-green algae under different nitrogen regimes. Phytochemistry 1984, 23:207-216.

3. Beley A, Kato T, Ota Y, Spirulina (Arthropira): Potential application as an animal feed supplement. J Appl Phycol 1996, 8:303-311.

4. Wijffels RH, Barbosa MJ: An outlook on microalgal biofuels. Science 2010, 329:796-799.

5. Leveille GA, Sauberich HE, Shockley JW: Protein value and the amino acid deficiencies of various algae for growth of rats and chicks. J Nutr 1962, 76:423-428.

6. Domozych DS, Stewart KD, Mattox KR: The comparative aspects of cell wall chemistry in the green algae (cholorphyta). J Mol Evol 1980, 15:1-12.

7. Becker EW: Micro-algae as a source of protein. Biotechol Adv 2007, 25:207-210.

8. Panjaitan T: Strategies to Enhance Efficiency of Microbial Protein Production in Cattle Consuming Tropical Forages. In Ph.D. Thesis. Brisbane, Australia: Schools of Animal Studies and Veterinary Science, University of Queensland; 2010.

9. Lum KK, Kim J, Lei XG: Dual potential of $s$ as a sustainable biofuel feedstock and animal feed. J Anim Sci Biotechnol 2013, 4:1-7.

10. AOAC: Official Methods of Analysis. 15th edition. Arlington, VA: Assoc Offic Anal Chem; 1990.

11. Robertson JB, Van Soest PJ: The Detergent System of Analysis and its Application to Human Foods. In The Analysis of Dietary Fiber. Edited by James WPT, Theander O. New York: Marcell Dekker; 1981:123-158.

12. Goering HK, Van Soest PJ: Forage Fiber Analysis (Apparatus, Reagents, Procedures and Some Applications), Agricultural Handbook no. 379. Washington, D.C: ARS-USDA; 1970.

13. Schofield $P$, Pitt RE, Pell AN: Kinetics of fiber digestion from in vitro gas production. J Anim Sci 1994, 72:2980-2991.

14. SAS Institute: SAS/STAT 9.2 User's Guide. 2nd edition. Cary, NC: SAS Inst; 2009.

15. Clark JH, Murphy MR, Crooker BA: Supplying the protein needs of dairy cattle from by-product feeds. J Dairy Sci 1987, 70:1092-1109.

16. McCormick ME, French DD, Brown TF, Cuomo GJ, Chapa AM, Fernandez JM, Beatty JF, Blouin DC: Crude protein and rumen undegradable protein effects on reproduction and lactation performance of Holstein cows. J Dairy Sci 1999, 82:2697-2708.

17. National Research Council: Nutrient Requirement of Dairy Cattle. 7th edition. Washington, D.C: Nat. Acad. Sci; 2001. 
18. Gupta UC, Gupta SC: Trace element toxicity relationships to crop production and livestock and human health. Commun Soil Sci Plant Anal 1998, 29:1491-1522.

19. National Research Council: Mineral Tolerance of Domestic Animals. Washington, D.C: Nat Acad Sci; 1980.

20. Getachew G, Robinson PH, DePeteers EJ, Taylor SJ: Relationships between chemical composition, dry matter degradation, and in vitro gas production of several ruminant feeds. Anim Feed Sci Technol 2004, 111:57-71.

doi:10.1186/2049-1891-5-31

Cite this article as: Han and McCormick: Evaluation of nutritive value and in vitro rumen fermentation gas accumulation of de-oiled algal residues. Journal of Animal Science and Biotechnology 2014 5:31.

\section{Submit your next manuscript to BioMed Central} and take full advantage of:

- Convenient online submission

- Thorough peer review

- No space constraints or color figure charges

- Immediate publication on acceptance

- Inclusion in PubMed, CAS, Scopus and Google Scholar

- Research which is freely available for redistribution 